\title{
Azelaic acid in the treatment of ocular and adnexal malignant melanoma
}

\author{
H. E. WILLSHAW AND K. RUBINSTEIN \\ From the Birmingham and Midland Eye Hospital, Birmingham
}

SUMMARY Following reports of the successful management of cutaneous malignant melanoma with azelaic acid both locally and systemically a trial was undertaken to assess its value in the treatment of similar lesions involving the eye and its adnexa. Systemically administered azelaic acid failed to influence the melanomata in any of the 4 patients included in the study. A plea is made for the reporting even of such disappointing results in the present uncertain climate.

The recent suggestion that enucleation of eyes harbouring malignant melanoma could precipitate dissemination of the tumour ${ }^{1}$ has provoked considerable debate as to the best management of such eyes. ${ }^{23}$ While it is recognised that ocular melanomata grow slowly in comparison with their cutaneous counterparts, ${ }^{2}$ nevertheless two independent followup studies on patients refusing enucleation have shown $100 \%$ of deaths from metastases. ${ }^{45}$ To many ophthalmologists, therefore, simply observing such lesions would be an unacceptable approach.

In this climate of uncertainty reports of a chemotherapeutic agent cytotoxic to cutaneous melanomata ${ }^{6}$ stimulated us to investigate its efficacity in ocular and adnexal malignant melanoma. We report our results in treating 4 patients with azelaic acid.

\section{Patients and methods}

All 4 patients were attending the Medical Ophthalmology Clinic at the Birmingham and Midland Eye Hospital and had either refused surgical intervention or, after detailed explanation, requested a trial with this agent prior to surgery. The diagnosis of malignant melanoma was agreed by the referring ophthalmologist and both authors prior to entry into the study. Detailed informed consent and a full medical history, with specific attention being paid to gastrointestinal, genitourinary, and dermatological symptoms, were obtained.

Correspondence to Mr H. E. Willshaw FRCS, Birmingham and Midland Eye Hospital, Church Street, Birmingham B3 2NS.
Each patient was examined by the authors to exclude clinical evidence of metastases or any unrelated systemic disorder, and a battery of investigations were performed including: haemoglobin and full blood count; urea, creatinine, and electrolyte levels; enzyme studies including SGOT, SGPT, creatinine kinase, and alkaline phosphatase; lactic dehydrogenase levels; and plasma protein analysis.

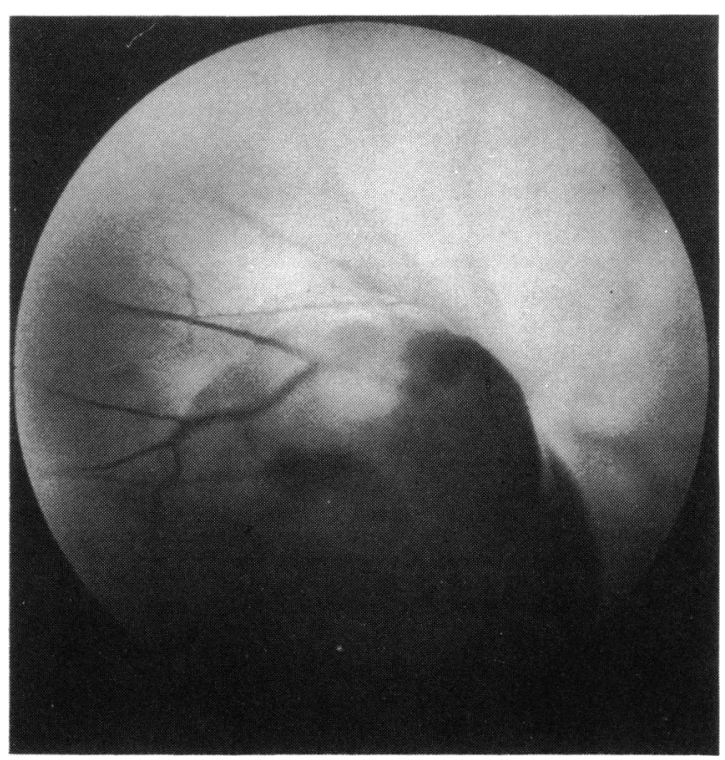

Fig. 1 Patient 1. Choroidal melanoma. 


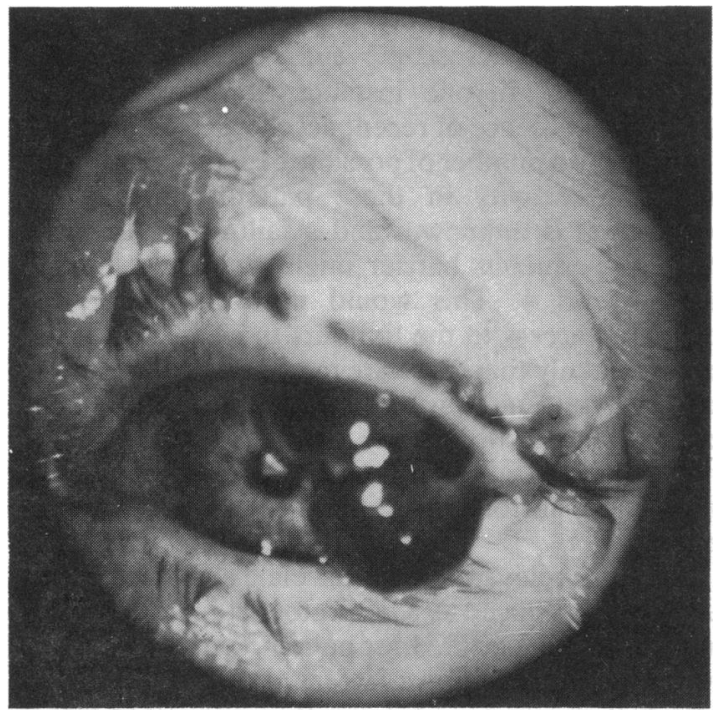

Fig. 2 Patient 2. Limbal melanoma.

The patients were then started on a regimen of $12 \mathrm{~g}$ of azelaic acid per day, in 4 divided doses, each comprising $5600 \mathrm{mg}$ capsules. The lesions were photographed prior to starting treatment and at each follow-up visit. The patients were reviewed after 2,4 , 8 , and 12 weeks, and at each review investigations were performed to exclude possible toxic effects. After 12 weeks the course of treatment was terminated and any further necessary action discussed with the patient.

\section{Case histories}

Case 1. Male, aged 64. Presented on 27 June 1980. A choroidal lesion had been found at routine optician's review. Right vision $6 / 9$, left vision $6 / 6$. Right choroidal malignant melanoma, diagnosed and considered unsuitable for radiotherapy (Fig. 1). Twelveweek course of azelaic acid failed to influence the bulk or pigmentation of the lesion. Right enucleation performed on 1 October 1980.

Histology. Spindle B and epitheliod cells, moderate pigment. No evidence of cell spaces or cytotoxic effect.

After 12 months remain well with $6 / 6$ vision in his left eye.

Case 2. Female, aged 68. Presented on 6 April 1979 following an episode of minor trauma to the left eyebrow. Area of left bulbar conjunctival melanosis found (Fig. 2). Lost to follow-up for 6 months. On 13 December 1979 the lesion had increased greatly in size. Exenteration refused.' Reviewed until 11 September 1980, when course of azelaic acid started. After 1 month her creatinine kinase was elevated and

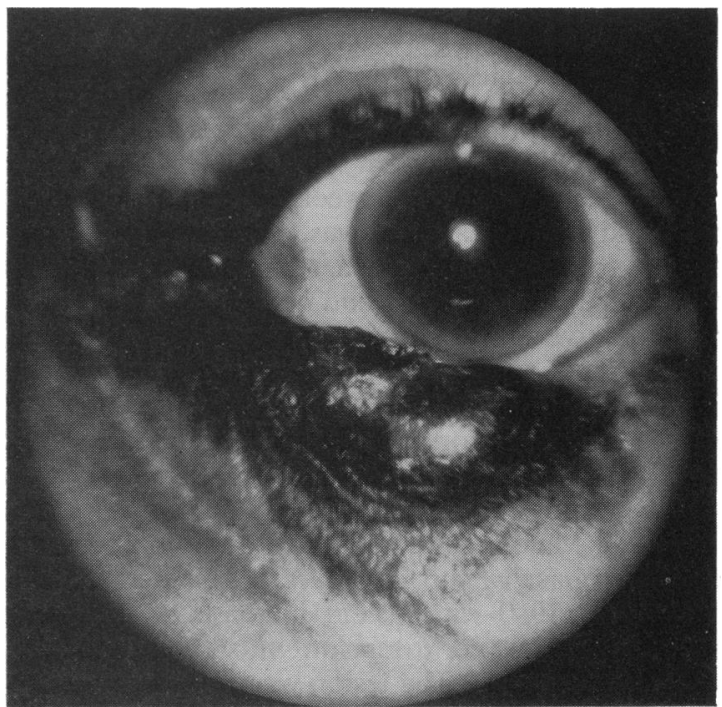

Fig. 3 Patient 3. Melanoma of lower lid.

she became hypokalaemic. During this month the lesion had increased in size, and she was persuaded to accept left enucleation with a wide conjunctival excision with grafting.

Histology. Highly anaplastic malignant melanoma of limbus arising from an area of intraepithelial melanosis. Actively mitotic but with no invasion of globe. Moderate to heavy pigmentation.

Review on 14 November 1981: well, with no evidence of recurrence.

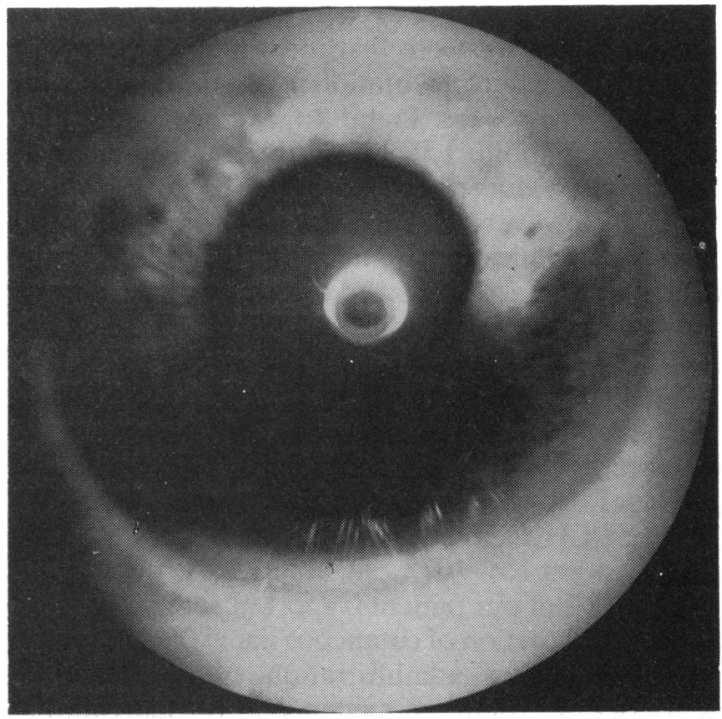

Fig. 4 Patient 4. Iris melanoma. 
Case 3. Female, aged 70. Presented on 10 March 1980 with heavily pigmented lesion left lower lid for 8 years (Fig. 3). Biopsy confirmed malignant melanoma, but exenteration refused. On 20 September 1980 treatment with azelaic acid started; course interrupted after 1 week because of epigastric pain and diarrhoea. This was considered to be unrelated to treatment, and therefore after one month the course was restarted and completed. There was no objective evidence of improvement, but at the patient's request treatment was continued for a further 3 months. Still no evidence of improvement by 5 April 1981. Therefore proceeded to exenteration.

Histology. Anaplastic malignant melanoma.

Lost to follow-up.

Case 4. Male, aged 53. Pigmented lesion on right iris inferonasally for 20 years. Presented on 11 September 1980 with recent increase in size, and gonioscopy showed extension into the trabecular meshwork (Fig. 4). The lesion was considered to be too extensive for local excision, and the patient requested a trial of chemotherapy prior to enucleation. Treatment with azelaic acid for 3 months failed to influence its size or pigmentation, and enucleation was performed.

Histology. Mixed spindle A and spindle B tumour with infiltration of iris, angle, and anterior ciliary body. No evidence of tumour regression or necrosis. One area of irregular scanty reticulin suggested recent rapid growth.

Review 18 months later found him well, with no recurrence, and $6 / 5$ vision in the fellow eye.

\section{Discussion}

Dicarboxylic acids were first identified as the active agents causing depigmentation in pityriasis versicolor in 1978. They were found to act as competitive tyrosinase inhibitors, ${ }^{7}$ and furthermore their synthetically produced counterparts have a similar action. However, intraperitoneal injections and cutaneous applications in mice with Harding-Passey virus melanoma also showed dicarboxylic acids to be cytotoxic to the tumour cells but with no systemic toxicity. ${ }^{8}$ Further studies ${ }^{9-11}$ confirmed the cytotoxic action in human cutaneous melanomata (and the absence of systemic toxicity) when the C9 dicarboxylic acid, azelaic acid, was used. The principal features of azelaic acid are $\mathrm{CH}_{2}$ $\left(\mathrm{CH}_{2} \mathrm{CH}_{2} \mathrm{CH}_{2} \mathrm{COOH}\right)_{2}$; molecular weight 188.23; melting point $104-107^{\circ} \mathrm{C}$; solubility $2 \cdot 8 \mathrm{~g} / \mathrm{l}$.

Though 2 of our patients reported some reduction of the pigmentation of cutaneous naevi (as one would expect following administration of a tyrosinase inhibitor), we found no evidence of depigmentation or bulk reduction in the tumours. Furthermore histology failed to show any evidence of depigmentation or microscopic cytotoxicity within the tumour mass. In one instance there was in fact suggestive evidence of recent accelerated growth.

There are a number of possible explanations for the lack of effectivity in these patients. Intraocular penetration is unknown, and a failure to penetrate the blood-aqueous barrier might explain failure in cases 1 and 4 . This would not, however, have prevented access to the tumours in cases 2 and 3 . It seems unlikely that there are major differences in the size of these tumours as compared to the cutaneous lesions treated successfully, ${ }^{6}$ and it is also unlikely that melanomata of both the globe and its adnexa show major histological differences from cutaneous lesions.

It may be relevant that the azelaic acid used in this series was produced as a laboratory standard powder and was much modified for patient consumption. Its purity and the reliability of its chemical characteristics were first checked, and it was then converted into a sodium salt to improve its solubility. Any of these manoeuvres may have removed or modified some associated factor which in previous work had proved beneficial.

Finally, while the agent was well tolerated by 3 patients, we suspected systemic toxicity in patient 2 , who developed a profound hypokalaemia $(2 \cdot 1$ $\mathrm{mmol} / \mathrm{l}$ ) while on treatment.

\section{CONCLUSION}

Given the current status of intraocular melanoma management, we feel exploration of potentially useful chemotherapeutic agents is justifiable. Care must be taken to obtain detailed consent, and it is important that even negative results be reported to avoid wasteful duplication of clinical investigative efforts. We have not found azelaic acid to be a useful chemotherapeutic agent in the management of ocular and adnexal malignant melanoma.

We thank Mr A. Broad, principal pharmacist. for preparing the azelaic acid, Dr R. Barry for performing the histology, our consultant colleagues for referring patients, and Mrs C. Rawlins for typing the manuscript.

\section{References}

1 Zimmerman LE, McLean, IW, Foster ND. Does enucleation of the eye containing a malignant melanoma prevent or accelerate the dissemination of tumour cells? Br J Ophthalmol 1978; 62: 420-5.

2 Manschot WA, Van Peperzeel HA. Choroidal melanoma, enucleation or observation? A new approach. Arch Ophthalmol 1980; 98: 71-7.

3 Zimmerman LE. Metastatic disease from uveal melanomas. A review of current concepts with comments concerning future research and prevention. Trans Ophthalmol Sóc UK 1980; 100: 34-54. 
4 Raivio I. Uveal melanoma in Finland: an epidemiological, clinical, histological and prognostic study. Acta Ophthalmol (Kbh) 1977; suppl 33: 45-6.

5 Sobanski J, Zeydler L, Goetz J. Uber die Therapie des intraokularen Melanoma malignum. Klin Monastsbl Augenheilkd 1965; 146: 70-6.

6 Nazzaro-Porro M, Zina G, Breathnach A, et al. Effect of azelaic acid on human malignant melanoma. Lancet 1980; i: 1109-11.

7 Nazzaro-Porro M, Passi S. Identification of tyrosinase inhibitors in cultures of pityrosporum. J Invest Dermatol 1978; 71: 205-8

8 Nazzaro-Porro M, Passi S, Morpurgo G, et al. Effect of dicarboxylic acids on Harding-Passey melanoma. $J$ Invest Dermatol 1978; 70: 235-7.

9 Nazzaro-Porro M, Passi S, Morpurgo G, et al. Identification of tyrosinase inhibitors in cultures of pityrosporum and their melanocytotoxic effect. In: Klaus S, ed. Pigment cell 4: Biologic basis of pigmentation. Basel: Karger, 1979: 234-43.

10 Nazzaro-Porro M, Passi S, Balus MD, et al. Effect of dicarboxylic acids on lentigo maligna. J Invest Dermatol 1979; 72: 296-305.

11 Breathnach AS, Martin B, Nazarro-Porro M, et al. Effect of dicarboxylic acids on normal human melanocytes in culture. $\mathrm{Br}$ Dermatol 1978; 99 (suppl 16): 19-20. 